\title{
Occipitalization of the atlas: Its incidence and clinical implications
}

\author{
Kimaporn Khamanarong ${ }^{1}$, Worawut Woraputtaporn ${ }^{1}$, Somsiri Ratanasuwan ${ }^{1}$, \\ Malivalaya Namking ${ }^{1}$, Wunnee Chaijaroonkhanarak ${ }^{1}$, Surachai Sae-Jung ${ }^{2}$
}

${ }^{1}$ Department of Anatomy, Faculty of Medicine, Khon Kaen University Khon Kaen, Thailand ${ }^{2}$ Department of Orthopedics, Faculty of Medicine, Khon Kaen University Khon Kaen, Thailand

Corresponding author: Kimaporn Khamanarong Department of Anatomy Faculty of Medicine Khon Kaen University Khon Kaen 40002

Thailand

kkimap@kku.ac.th

Tel.: + 66847933178

Fax.: + 6643348381

Received: 24 January 2013

Accepted: 17 April 2013

Copyright (c) 2013 by Academy of Sciences and Arts of Bosnia and Herzegovina.

E-mail for permission to publish: amabih@anubih.ba

\begin{abstract}
Objective. The aim of the present study was to investigate the incidence of occipitalization of the atlas among Thai dried skulls, in order to contribute to baseline awareness of this condition. Materials and methods. The skulls of 633 adult Thais from the collection maintained in the Department of Anatomy, Faculty of Medicine, Khon Kaen University, Thailand, were examined for evidence of occipitalization of the atlas. The skulls were well-preserved and did not show any traits of craniofacial deformation. The skulls for which the age and sex were unknown were excluded from the analysis. From the cadaveric records on each individual, we learned that the skulls belonged to 373 men (age of decease between 25 and 90 years), and 260 women (age of decease between 28 and 92 years). Results. Occipitalization of the atlas was detected in 2 skulls $(0.32 \%)$. The first case was a male skull (54 years of age at decease), where the atlas was partially fused to the occipital bone. The second case was also a male skull (59 years of age at decease) showing complete fusion of the anterior arch of the atlas. Conclusion. The incidence of occipitalization of the atlas is low; however, if present this abnormality may cause a wide range of neurological problems. Knowledge of occipitalization of the atlas may be of substantial importance to orthopedists, neurosurgeons, physiotherapists and radiologists dealing with abnormalities of the cervical spine. Mistaken diagnoses have led to delayed treatment and at times adverse results.
\end{abstract}

Key words: Occipitalization, Atlas, Incidence, Neurological problems.

\section{Introduction}

Occipitalization of the atlas, or atlanto-occipital fusion, is one of the most common skeletal abnormalities found at the craniocervical junction (1). Occipitalization is caused by assimilation of the first cervical vertebra (the atlas) into the basicranium (2, 3 ). The incidence ranges between 0.14 and $3.63 \%(4-9)$ and it can be partial or complete
(10-12), with the latter being the most common (13). Multiple variations of partial occipitalization have been reported, and many involve some aspect of atlanto-occipital articulation (14). Atlantal occipitalization may be congenital or acquired (15). Most of the mechanism of occipitalization is believed to be the malformation of the embryological development of the upper axial skeleton (16). Congenital malformation of the 
cervico-occipital region is of considerable consequence because of its proximity to the spinomedullary region, with the possibility of neurological compression syndrome. Occipitalization of the atlas can produce a wide range of neurological signs and symptoms, which vary from a transitory headache to a full-blown neurological syndrome (17), leading to occipitocervical instability. The onset of neurological symptoms is usually in the third or fourth decade. The presence of blocked vertebrae below this level may accelerate the development of symptoms, due to compensatory motion at the atlantoaxial joint (6).

Standard anatomy text books do not pay much attention to occipitalization of the atlas, and research on it is the only source of information (4). Thus, the aim of the present study was to investigate the incidence of occipitalization of the atlas among Thai dried skulls, in order to contribute to baseline awareness of this condition.

\section{Methods}

We examined 633 skulls of adult Thais from the bone collection maintained in the Department of Anatomy at the Faculty of Medicine, Khon Kaen University, Thailand. The skulls were well preserved and did not show any trait of craniofacial deformation. The external and internal surfaces of the entire occipital bone were observed by visual inspection. The age and sex of the deceased were recorded by the technicians. The skulls for which the age and sex were unknown were excluded from the analysis. From the cadaveric records on each individual, we learned that the skulls belonged to 373 men (age of decease between 25 and 90 years), and 260 women (age of decease between 28 and 92 years). All of the skulls came from individuals who had donated their bodies to the Department. The proposal for this research project was approved by the Re- search and Ethics Committee of the Faculty of Medicine, Khon Kaen University.

\section{Results}

Of the 633 dried occipital bones, occipitalization of the atlas was found in two subjects $(0.32 \%)$. The first case was a male skull (54 years of age at decease), where the atlas was partially fused to the occipital bone (Figure 1).

The posterior arch was incompletely fused in the midline. The anterior arch of the atlas was completely fused with the basilar part of the occipital bone, except for a slitlike opening above the anterior tubercle. The lateral masses were completely fused to the occipital bone. The superior articular facets of the atlas were totally fused to the occipital bone in the region of the occipital condyles. The left transverse process had no foramen transversarium. The respective maximum vertical length and transverse width of the right vs. left inferior articular facets were 19 and $14 \mathrm{~mm}$, vs. 17 and $16 \mathrm{~mm}$. The respective transverse and sagittal diameter of the foramen magnum were 25.4 and $28 \mathrm{~mm}$.

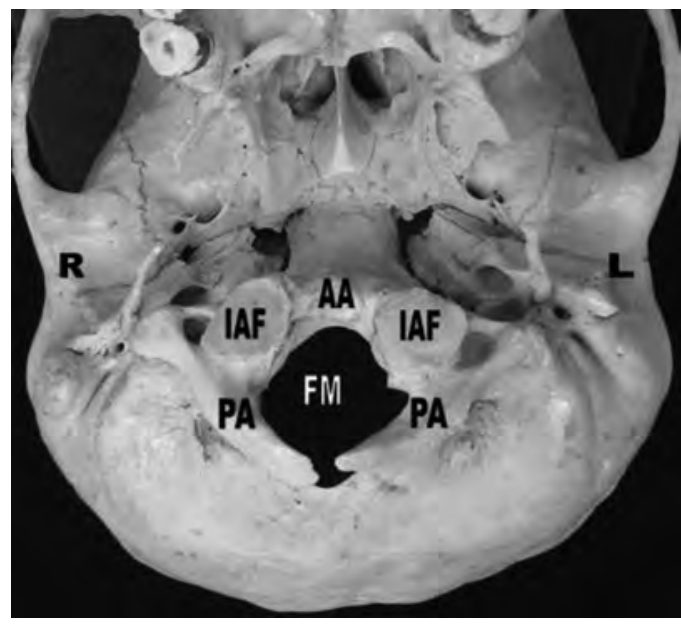

Figure 1 Photograph of the base of the skull showing a central deficit of the posterior arch of the atlas and fusion existing between the occipital bone and the right and left parts of the posterior arch. ( $R$ - right side, $L$ - left side, $A A$ - anterior arch of the atlas, IAF - inferior articular facets of the atlas, FM foramen magnum, PA - posterior arch of the atlas). 


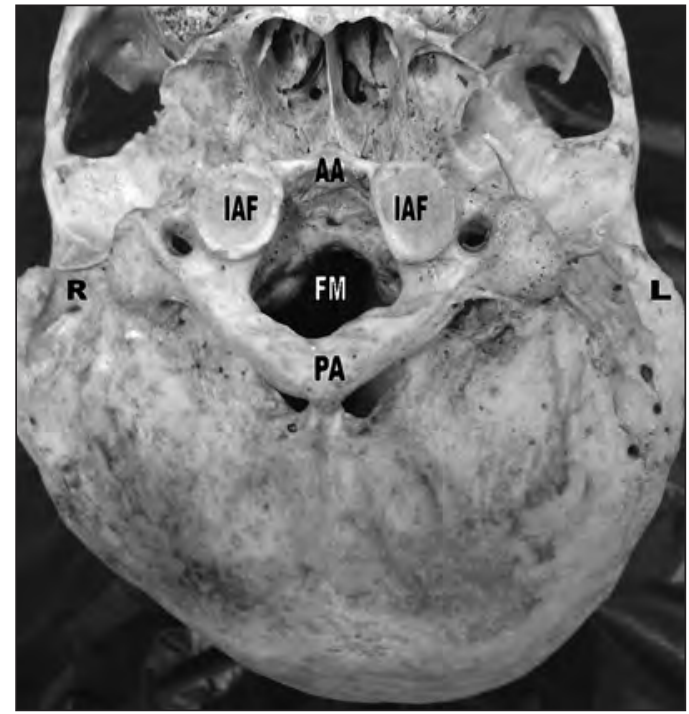

Figure 2 Photograph of the base of the skull showed fusion between the occipital bone and the right and left parts of the posterior arch and the posterior tubercle. ( $R$ - right side, $L$ - left side, $A A$ - anterior arch of the atlas, IAF - inferior articular facets of the atlas, FM - foramen magnum, PA - posterior arch of the atlas).

The second case was also a male skull (59 years of age at decease) showing complete fusion of the anterior arch of the atlas (Figure 2).

The posterior arch was also fused with the squamous part of the occipital bone. There were some perforations between the posterior arch and the occipital bone. The lateral masses were completely fused to the occipital bone. Both the left and right superior articular facets of the atlas were fused with the corresponding occipital condyles. The respective maximum vertical length and transverse width of the right vs. left inferior articular facets were 18 and $16 \mathrm{~mm}$, vs. 20 and $15 \mathrm{~mm}$. The respective transverse and sagittal diameter of the foramen magnum were 26.2 and $32.6 \mathrm{~mm}$.

\section{Discussion}

The cause of occipitalization of the atlas may be congenital or acquired (15). The acquired cases may be due to tuberculosis (16) or other infectious disease. They may also re- sult from mechanical injuries of the cervical region of the vertebral column. The injuries may concern ligaments and/or bones. By comparison, the congenital causes are connected with the appearance of disorders (teratogenic factors, genetic anomalies) during the third week of fetal life, when the occipital and cervical sclerotomes are developing. Occipitalization of the atlas takes place if the first cervical sclerotome does not divide into the cranial and caudal components, and the atlas gets assimilated into the occipital components, because the caudal part of the fourth occipital sclerotome unites with the whole first cervical sclerotome $(7,16)$.

Atlanto-occipital fusion can cause numerous neurological deficits because the dimensions of the foramen magnum undergo reduction. The symptoms concomitant with occipitalization are connected with compression on the medulla oblongata, spinal cord, vertebral artery and venous plexus (10, 17). The sagittal diameter of the foramen magnum is a crucial landmark in symptomatic patients (18). In our second case, this diameter was considered abnormal as it was $<30 \mathrm{~mm}$ (18). This can lead to clinically manifesting symptoms.

Vega et al. (19) reported that the range of the transverse diameter of the foramen magnum is between $28-40 \mathrm{~mm}$. The respective transverse diameter of the foramen magnum of both of our cases was narrower than the normal range. This report is in agreement with Sani et al. (9), Tun et al. (12) who reported that narrowing of the foramen magnum is associated with brainstem compression. The main reason is the high position of the dens in relation to the medulla oblongata $(7,16)$. The chief symptoms associated with assimilation of the atlas are headache, neck pain, abnormal posture of head and neck, restricted head and neck movements, numbness or pain in the extremities, weakness of lower limb, disturbances in balance and ataxia $(7,17)$. According to Hensinger 
(1), a patient with occipitalization of the atlas will have a short neck and restricted neck movement. The vertebral artery may be compressed and symptoms-such as dizziness, seizure, mental deterioration and syncope-may occur.

Detection and treatment of this deformity are essential as this deformity often causes cervical spine instability. Special imaging, such as CT scan, three-dimensional CT scan, or MRI should be obtained before surgery. Tun et al. (12) reported a case in which CT images revealed not only a fusion between the posterior arch of the atlas and the occipital bone, but also hypertrophy of the occipital condyles and a reduction in the transverse diameter of the foramen magnum.

Spontaneous occipito-atlantal fusion, and anomalies of the occipital condyles (20) can cause changes in the biomechanics of the craniovertebral junction. In odontoid fracture or C1-C2 instability associated with rheumatoid arthritis, the occipito-atlantal fusion moves as a single unit, leading to more displacement of the odontoid process and more instability of the craniovertebral junction. The occipito-atlantal fusion must, therefore, be considered when operating on patients with C1-C2 instability-such as C1-C2 instability associated with odontoid fracture or rheumatoid arthritis. In these situations, preoperative X-rays, CT scan and MRI are recommended to determine the associated bone anomaly (21) and to ensure a complete preoperative evaluation (22). The instrumentation and arthrodesis must be fixed from the occiput to the $\mathrm{C} 2$, instead of the $\mathrm{C} 1-\mathrm{C} 2$ fixation, as is more common.

In previous studies done on Asians (3, 4, 9,23 ), and including the present study, only two skulls were detected showing occipitalization of the atlas. The respective incidences were $2.04,3.63,1.59,0.69$ and $0.32 \%$. The relatively low frequency found in the current study was due to the higher total number of cases (633), while the others examined fewer cases ( $\mathrm{n}=98,55,150$ and 126, respectively).

\section{Conclusion}

Occipitalization of the atlas is the most common anomaly of the craniocervical junction, hence head and neck surgeons should be aware that such an anomaly may exist without any typical symptoms. Restriction or absence of movement in this articulation may be the first sign which attracts their attention regarding such assimilation. Knowledge of occipitalization of the atlas may be of substantial importance to orthopedists, neurosurgeons, physiotherapists and radiologists dealing with abnormalities of the cervical spine. Mistaken diagnoses have led to delayed treatment and at times adverse results.

Acknowledgements: We thank (a) the many Thais who donated their bodies to the Department of Anatomy, Faculty of Medicine and their families for granting permission (b) the staff of the Bone Museum in the Department of Anatomy and (c) Mr. Bryan Roderick Hamman and Mrs. Janice Loewen-Hamman for assistance with the English-language presentation of the manuscript.

Authors' contributions: Conception and design: KK Acquisition, analysis and interpretation of data: RS, CW; Drafting the article: KK; Revising it critically for important intellectual content: WW, NM.

Conflict of interest: The authors declare that they have no conflict of interest.

\section{References}

1. Hensinger RN. Osseous anomalies of the craniovertebral junction. Spine. 1986;11(4):323-32.

2. Jayanthi V, Kulkarni R, Kulkarni RN. Atlantooccipital fusion- report of two cases. J Anat Soc India. 2003;52(1):71-3.

3. Ranade AV, Rai R, Prabhu LV, Kumaran M, Pai MM. Atlas assimilation: a case report. Neuroanatomy. 2007;(6):32-3.

4. Kassim NM, Latiff AA, Das S, Ghafar NA, Suhaimi FH, Othman F, et al. Atlanto-occipital fusion: an osteological study with clinical implications. Bratisl Lek Listy. 2010;111(10): 562-5. 
5. Von Torklus D, Gehle W. The upper cervical spine, regional anatomy, pathology and traumatology. In: Verlag GT, editor. A systemic radiological atlas and textbook. New York: Grune \& Stratton; 1972. p. 2-77.

6. Guebert GM, Yochum TR, Rowe LJ. Congenital anomalies and normal skeleton variants. In: Yochum TR, Rowe LJ, editors. Essentials of skeletal radiology. Baltimore: Williams \& Wilkins; 1987. p. 197-306.

7. Al-Motabagani MA, Surendra M. Total occipitalization of the atlas. Anat Sci Int. 2006;81(3):173-80.

8. Heggeness MH. Embryology and developmental anomalies. In: Esses SI, editor. Textbook of spinal disorders. Philadelphia: JB Lippincott; 1995. p. 35-48.

9. Sani V, Singh R, Bandopadhyay M, Tripathi SK, Shamal SN. Occipitalization of the atlas: its occurrence and embryological basis. Int J Anat Variat. 2009;(3):85-8.

10. Gholve PA, Hosalkar HS, Ricchetti ET, Pollock AN, Dormans JP. Drummond DS. Occipitalization of the atlas in children. Morphologic classifications, association, and clinical relevance. J Bone Joint Surg Am. 2007;89(3):571-8.

11. Nicholson J, Sherk H. Anomalies of the occipitocervical articulation. J Bone Joint Surg Am. 1968;50(2):295-304.

12. Tun K, Okutan O, Kaptanoglu G, Gok B, Solaroglu I, Beskonakli E. Inverted hypertrophy of occipital condyles associated with atlantooccipital fusion and basilar invagination: a case report. Neuroanatomy. 2004;(3):43-5.

13. Wackenhein A. Roentgen diagnosis of the craniovertebral region. New York: Springer-Verlag; 1974. p. 360-2.
14. Von Torklus D, Gehle W. The upper cervical spine. London: Butterworth; 1974.

15. Erdil H, Yildiz N, Cimen M. Congenital fusion of cervical vertebrae and its clinical significance. J Anat Soc India. 2003;52(2):125-7.

16. Black S, Scheuer L. Occipitalization of the atlas with reference to its embryological development. Int J Osteoarchaeol.1996;6(2):189-94.

17. Nayak S, Vollala VR, Raghunathan D. Total fusion of atlas with occipital bone: a case report. Neuroanatomy. 2005;(2):39-40.

18. Hayes M, Parker G, Ell J, Sillence D. Basiar impression complicating osteogenesis imperfacta type IV: the clinical and neurological findings in four cases. J Neurol Neurosurg Psychiatry. 1999;(66):357-64.

19. Vega A, Quintana F, Berciano J. Basichondrocranium anomalies in adult Chiaritype 1 malformation: a morphometric study. J Neurol Sci. 1990; (99):137-45.

20. Das S, Suri R, Patil R J, Kapur V. Unusual occipital condyles of the skull: an osteological study with clinical implications. Sao Paulo Med J. 2006;124(5):278-9.

21. Skrzat J, Mroz I, Jaworek JK, Walocha J. A case of occipitalization in the human skull. Folia Morphol (Warsz). 2010;69(3):134-7.

22. Harcourt BT, Mitchell TC . Occipitalization of the atlas. J Manipulative Physiol Ther. 1990;3(9):532-8.

23. Jadha V, Ambali M, Patil RJ, Dosti MA, Roy PP. Assimilation of atlas in Indian dry skull: a case report. J KIMSU. 2012;1(1):102-6. 